\title{
OPPOSITES IN A DIALOGICAL SELF: CONSTRUCTS AS CHARACTERS
}

\author{
HUBERT J. M. HERMANS \\ University of Nijmegen, Nijmegen, The Netherlands
}

\begin{abstract}
Bakhtin's (1973) polyphonic novel serves as a metaphor for a dialogical conception of the self. In line with this metaphor, it is argued that a narrative approach leads to a multivoiced conception of the self, in which the poles of a personal construct are related as opposing characters positioned in an imaginal space. In this space, the I fluctuates among positions in a dialogical fashion. Two main features of the relation between positions are discussed: intersubjective communication and dominance. These features form the basis of a theory and methodology that have led to the discovery of a particular phenomenon: dominance reversal. This phenomenon represents a radical change in the dominance relation of contrasting positions within a limited time period, in an apparent absence of causal factors. The implications of this phenomenon for the organization and reorganization of the self are discussed.
\end{abstract}

The experience of opposites is a dynamic phenomenon par excellence. The existence of polar opposites in the human mind requires an ordering, in which the contrasting elements are combined, reconciled, separated, or treated in some other way. Not surprisingly, the existence of opposites and their organization have received special attention in psychological theories, from both the social and clinical perspectives.

From the perspective of social psychology, Festinger (1957) observed that people, striving toward consistency within themselves, try to remove inconsistencies among opposing or conflicting attitudes concerning a particular subject. On the basis of this observation, Festinger formulated the hypothesis that "the existence of dissonance, being psychologically uncomfortable, will motivate the person to try to reduce the dissonance and achieve consonance" (p. 3). In a similar vein, Heider (1958) dealt with the contrast between positive and negative evaluations of persons and objects. Instead of the terms consonance and dissonance, he used the terms balance and imbalance. A balanced

Received 11 May 1994; accepted 3 February 1995.

I thank Sue Houston for her detailed editorial comments.

Address correspondence to Hubert J. M. Hermans, Department of Clinical Psychology and Personality, University of Nijmegen, P.O. Box 9104, 6500 HE Nijmegen, The Netherlands. 
state is characterized by harmonious relations between elements and an imbalanced state by contrasting, or nonfitting, relations. If a balanced state does not exist, forces toward this state will be mobilized, because a continuation of a state of imbalance will produce tension. A related development was Osgood and Tannenbaum's (1955) principle of congruity: "Changes in evaluation are always in the direction of increased congruity with the existing frame of reference" (p. 43). When incongruity is felt between perceived elements, there is a pressure in the direction of increased congruity. Thus Festinger, Heider, and Osgood and Tannenbaum concurred that a state of dissonance, imbalance, or incongruity creates a tension that motivates the person to change the relation between perceived elements in such a way that tension is reduced.

Whereas the classic theorists in social psychology concentrated on the process of tension reduction between polar opposites, a diversity of early authors, mainly with a clinical orientation, emphasized the importance of synthesis, or reconciliation, of opposites (McAdams, 1985). They shared the idea that psychological contrasts are in one way or another mutually complementary and, as such, a necessity for the development of a mature self. Jung is probably the most notable theorist in the clinical field who conceived of personality as an organization of opposites. Jung argued that the domain of the conscious stands in opposition to the domain of the unconscious, the individual unconscious stands in opposition to the collective unconscious, extroversion is opposed to introversion. Archetypes are often arranged as opposites: the wise old man, or senex, versus the child, or puer; the earth mother versus the sky father. From a clinical-developmental perspective, Jung (1959) devised the concept of individuation to comprehend the basic human tendency to develop in the direction of a synthesis of polar opposites. In the process of individuation, opposites come to be reconciled as the result of a maturing self. The integration of the self is an accomplishment usually saved for the second half of life (Jung, 1959).

Sullivan's (1953) concept of personification is another influential example of personality organization in which opposites play a central role. According to Sullivan, personified images of the self, such as the "good me" and the "bad me," and personified images of others, such as the "good mother" and the "bad mother," are organized together into the child's self-system. These personified images enable the child to orchestrate his or her interactions with the environment in such a way as to minimize anxiety. As the child grows older, the good mother and the bad mother fuse, together with other aspects of the mother, into larger configurations. Such a configuration develops into a more integrative representation of the mother as a whole. For a related 
view, see discussions of the concept of internalization in the objectrelations literature (Fairbairn, 1952; Guntrip, 1971; Jacobson, 1964; Klein, 1948) and of the three ego states-"parent," "adult," and "child,"-in the transactional analysis literature (Berne, 1972; Steiner, 1974).

In addition to Jung and Sullivan, a variety of students of human nature have argued that maturation of the self involves a reconciliation of opposites. Bakan (1966) argued for a balance between agency (self-maintenance and self-expansion) and communion. Adler (1922) considered not only perfection but also Gemeinschaftsstreben (striving for community) as personal goals of human development. Angyal (1965) discussed the balance between two mutually complementing forces: autonomy (self-determination) and homonomy (self-surrender). Similarly, Loevinger (1976) described the reconciliation of autonomy and interdependence at the highest stages of ego development. Klages (1948) considered Bindung (solidification) and Lösung (dissolution) as two complementary components of human character. From a clinicaldevelopmental point of view, Gutmann (1980) observed a blending of masculinity and femininity after midlife. In a study of mystic and meditative experiences, Deikman $(1971,1976)$ distinguished between an action mode and a receptive mode of consciousness and emphasized that the mature person is able to alternate between the two. Fowler (1981) described the rapprochement of the rational and the ecstatic at the highest stage of human faith.

As the preceding review suggests, both academic social psychology and clinical-developmental treatises on the self show a clear interest in the phenomenon of opposites in human experience. There is, however, a notable difference between the two streams of thought. The academic tradition is mainly interested in the analysis of judgment and in the process of tension reduction. In the process of tension reduction, one of the contrasting elements becomes dominant over the other one so that the specific position of the other (incompatible) element is given up. In contrast, the clinical-developmental tradition considers polar opposites as mutually complementing and is focused on their synthesis as a necessity for a maturing self. As far as there is a tension between the polar opposites, it is not reduced but rather functions as a challenge for their integration. In principle, the two elements of a pair of opposites are treated as equally important and as mutually fertilizing.

Kelly's (1955) work occupies a special position with reference to the preceding classification. Apart from the fact that he can be considered both a social psychologist and a clinical psychologist, his treatment of opposites has certain similarities with both the social and clinical groups. The implication of opposites in a personal construct is most 
clearly expressed in the Dichotomy Corollary, which states that a person's construction system is composed of a finite number of dichotomous constructs. Both parts of this dichotomy are essential for the definition of the construct, with the implication that a construct system is, on a priori grounds, organized along opposites. In this respect, Kelly's view corresponds clearly with the clinical tradition that considers polar opposites as mutually defining and complementing. On the other hand, Kelly (1955) gave explicit attention to the role of tension reduction in close correspondence with a discussion of anxiety. In the face of anxiety, an individual may, as a protective device, "submerge" one end of a construct or suspend elements of it that do not fit well into a particular construct. In this respect, Kelly was close to the social psychological theorists when they observed that uncomfortable feelings associated with a state of dissonance lead to tension reduction and to the dominance of one oppositional pole over the other.

In the spirit of Kelly, in this article, I treat the poles of a construct not only as mutually complementary and defining, but also in their relative dominance, one pole temporarily taking precedence over the other. In one respect, however, I move beyond the Dichotomy Corollary. I consider the two poles of a personal construct as if they were characters involved in dialogical relationships. As interacting characters in a narrative, the two poles are considered as protagonist and antagonist and therefore as belonging together in mutually complementary and defining ways. At the same time, I suppose that the characters are involved in dominance relationships, with one taking a more prominent position in the dialogue than the other. In fact, this means that I follow the two characters over time, paying special attention to changes in their relative dominance.

Herein I give an exposition of Bakhtin's (1929/1973) metaphor of the "polyphonic novel," which lays a foundation for the use of the term self-narrative, in which opposing "characters" are dialogically related. I argue that these characters tell their specific self-narratives in terms of contrasting systems of personal valuations (units of meaning). I conclude the article with an idiographic study that illustrates the presented theoretical framework, paying special attention to the relative dominance of the characters and their changes over time.

\section{THE POLYPHONIC NOVEL AS A METAPHOR FOR THE DIALOGICAL SELF}

In Problems of Dostoyevsky's Poetics, the Russian literary scholar Mikhail Bakhtin (1929/1973) proposed that Dostoyevsky, one of the most bril- 
liant innovators in the history of novelistic literature, introduced a new artistic form, the polyphonic novel. The importance of Bakhtin's work for psychology has recently been discussed by Vasil'eva (1988), Florenskaya (1989), Wertsch (1991), and Hermans and Kempen (1993). Bakhtin's ideas represent a significant contribution to understanding the dialogical nature of the self and may be elaborated on by more recent psychological work.

The principle feature of the polyphonic novel is that it is composed of a number of independent and mutually opposing viewpoints embodied by characters involved in dialogical relationships. The interacting characters are not to be seen as the creation of one author, Dostoyevsky himself, who as an omniscient author is "above" his characters and understands them from a centralized viewpoint. Rather, each character is "ideologically authoritative and independent," that is, the author of his or her own legitimate ideological position. The characters are not slaves to Dostoyevsky's artistic intentions, but are capable of standing beside their creator, disagreeing with him, even rebelling against him.

Bakhtin (1929/1973) held that in Dostoyevsky's novels there is not one single author, but several authors or thinkers-Myshkin, Stavogin, Raskolnikov, Ivan Karamazov, the Grand Inquisitor-each having his own voice and telling his own story. These characters do not function within a unified objective world, subordinated to Dostoyevsky's individual vision, but are "a plurality of consciousnesses," represented by voices who come across as the authors of their own ideology. When different characters meet one another within the framework of a book, they oppose and accompany one another in a dialogical fashion. As in a polyphonic musical composition, the several voices have different spatial positions and accompany and oppose each other in a dialogical relation.

\section{Logical Versus Dialogical Relationships}

For a proper understanding of the notion of dialogue, it is necessary to establish the difference between logical and dialogical relationships. Bakhtin (1929/1973) gave the example of two completely identical phrases, "life is good" and "life is good." When one considers these phrases from the perspective of Aristotelian logic, they are related in terms of identity. In fact, they are one and the same statement. From a dialogical point of view, however, they are two remarks expressed by the voices of two spatially separated people in communication, who in this case have a relationship of agreement. The phrases 
are identical from a logical point of view but different as utterances: The first is a statement and the second a confirmation. Similarly, the phrases "life is good" and "life is not good" can be compared. From a logical perspective, one is a negation of the other. As utterances from two different speakers, however, they are part of a dialogical relation of disagreement. The relationship of agreement and disagreement is, like a question and answer, a basic dialogical form. To prevent misunderstanding of Bakhtin's position, I wish to add that he certainly did not reject the rules of logic. Instead, he concluded: "Dialogical relationships are totally impossible without logical and concrete semantic relationships, but they are not reducible to them; they have their own specificity" (Bakhtin, p. 152).

Dostoyevsky's novel The Double is an example of the working of dialogical relationships. In this novel, the second hero (the double) is to be understood as a personification of the interior voice of the first hero (Golyadkin). Externalization of the "inner" thought of the first hero into an utterance of the second hero results in the spontaneous occurrence of dialogical relations between the two parties. The externalization of the interior voice of the first hero in a spatially separated opponent creates a situation in which the two heroes and their thoughts are not simply identical but differ as a result of their spatial opposition. In the resulting dialogue, each character can tell, as an independent author and from a specific position, a story about him- or herself. Along these lines, Bakhtin (1929/1973) realized a "spatialization of the psyche" that he summarized in this way: "This persistent urge to see all things as being coexistent and to perceive and depict all things side by side and simultaneously, as if in space rather than time, leads him [Dostoyevsky] to dramatize in space even the inner contradictions and stages of development of a single person" (p. 23). In this narrative construction, a plurality of consciousness is presupposed and, correspondingly, a plurality of worlds that are neither identical nor unified but rather heterogeneous and even opposed. With this device, Dostoyevsky portrays characters conversing with the devil (Ivan and the devil), with their alter egos (Ivan and Smerdyakov), and even with caricatures of themselves (Raskolnikov and Svidrigailov).

An apparent feature of logical relationships is that they are "closed" insofar as they do not permit any conclusion beyond the limits of the rules that govern the relationship. Once the identity or negation thesis has been applied to a set of statements, there is nothing left to be said; neither is an opening created to the domain of the unexpected and unexplored. The openness of consciousness in Dostoyevsky's heroes, in contrast, continuously resists any final conclusion: "His selfconsciousness lives on its unfinalizedness, its open-endedness and in- 
determinacy" (Bakhtin, 1929/1973, p. 43), and "every thought of Dostoevsky's heroes ... feels itself to be a speech in an uncompleted dialog" (Bakhtin, 1929/1973, p. 27). For Bakhtin (1929/1973), openness was an intrinsic feature of dialogue and its recognition a necessary condition for the understanding of individual life: "The genuine life of the personality can be penetrated only dialogically, and then only when it mutually and voluntarily opens itself" (p. 48).

The conception of dialogue that is central to Bakhtin's (1929/1973) theory is not only open and "unfinalized," but also highly personal. Dostoyevsky's world is "profoundly personalized" and each character is a "concrete consciousness, embodied in the living voice of an integral person" (Bakhtin, p. 7). A particular utterance is never isolated from the consciousness of a particular spatially localized character. Moreover, the utterance of one particular character is always implicitly or explicitly, in reality or imagination, responding to that of another character, and therefore, "a dialogical reaction personifies every utterance to which it reacts" (Bakhtin, p. 152). Whereas logical statements, based on impersonal rules as they are, can be easily isolated from the speaker, this is impossible for dialogical utterances. Dialogues can be understood only when the particularities and personal intentions of the two interactors are taken into account.

\section{Dialogue and the Contact with Imaginal Others}

In an extensive discussion of the role of "invisible guests" in the self, Watkins (1986) argued that in most psychological theories, imaginal phenomena are most often approached from the perspective of the real. Ontological priority is clearly given to the existence of real others and to "reality" in general, whereas imaginal others are typically seen as derivative from and subordinate to this "objective" reality. Nevertheless, our daily lives are filled with imaginal dialogues. Taking place alongside actual dialogues with real others and interwoven with them, they constitute a central part of our narrative construction of the world. Even when we are outwardly silent, we may be communicating with our parents, our critics, our consciences, our gods, our reflection in the mirror, with the photograph of someone we miss, a figure from a movie or a dream, our babies, or our pets. One could even argue that we are never completely alone, because there are always inner conversations with imaginal others, or at least a longing for contact with those others.

Despite their invisible quality, imaginal others are typically perceived as having a spatially separated position. This is true not only of 
our own culture (e.g., imaginal contact with a wise advisor, a deceased parent or friend or an ideal lover), but also of non-Western communities. As Warneck (1909; cited by Watkins, 1986) has described, the Bataks of Sumatra hold the belief that the spirit, who determines the character and fortune of a person, is a person within a person, a special being with its own will and desires. Similarly, Cassirer (1955) emphasized that in mythical consciousness, a tutelary spirit is conceived not as the central core of someone's inner life, but as something with its own existence, "which dwells in man, which is spatially connected with him and hence can also be spatially separated from him" (cited by Watkins, 1986, p. 93).

The role of imaginal interactions, in both Western and non-Western cultures, has received special attention from cultural anthropologists. One of them, Caughey (1984), did fieldwork in Micronesia and Pakistan and observed that imaginal interactions were in no way restricted to non-Western cultures. By his estimation, the "real" social world of most North Americans includes between 200 and 300 people (e.g., family, friends, acquaintances, and colleagues) and, besides these real others, a vast number of imaginal others. Caughey classified these imaginal others into three groups: (a) media figures with whom the individual engages in imaginal interactions; (b) purely imaginary figures produced in dreams and fantasies; and (c) imaginal replicas of parents, friends, or lovers who are treated as if they were really present. Caughey demonstrated, as Watkins (1986) did, that imaginal dialogues and interactions exist side by side with real interactions (e.g., "What would my father say if he saw me now?") and may or may not have a direct link with reality.

Caughey (1984) argued that the conflation of "social relationships" with only "actual social relationships" is based on "an ethnocentric projection of certain narrow assumptions in Western science" (p. 17). Not surprisingly, he preferred to speak of an imaginal "social world," rather than a purely "inner world" in order to emphasize the interaction with someone who is felt to be "there," as a fellow member of a spatial configuration of which the person intrinsically feels a part. A similar view was expressed by Bruner (1986), who criticized the phrase "private self," for the reason that the self, even in its most inner realms, is never purely private.

\section{Dialogue and Dominance}

In a study of the interplay of participants' initiatives and responses in conversations, Linell (1990) observed emergent patterns of symmetry 
versus asymmetry (or dominance). Along with Wrong (1968), Linell maintained that asymmetry exists in each individual act-response sequence. The speaker has a certain privilege in being able to take initiatives and display his or her view. This privilege, however, is not the permanent "ownership" of only one party involved in the interaction. In the continuous reciprocity of influence, the actors continually alternate the roles of "power holder" and "power subject." In other words, turn-taking is inherent in conversational interaction, and this implies that as long as the conversation develops, the interactors are dominant in turn.

A second reason why conversations are more or less asymmetrical follows from the fact that they are always embedded in a broader social context. In the tradition of Bakhtin and Vygotsky, who were concerned with intersubjectivity from a cultural and historical perspective, Linell (1990) emphasized that meanings in interaction are not entirely constructed ab novo. Because interactions are culturally and institutionally structured and prescribed, dialogical relationships characteristically differ in these role alternations. Under the influence of these prescriptions, one party comes out as more dominant than the other. Parents, for example, are in a position to make extensive use of the dominance aspect of the dialogue in relation to their children. Bruner (1985) observed that in conversing with a small child, an adult serves almost as the vicarious consciousness of the child. The adult behaves as if he or she is the only one who knows the goal of the activity in which the two of them are engaged. It is quite easy for parents to "steal" the child's turn or to correct or reformulate the child's contribution. In a study of pediatric consultations in an allergy clinic, Aronsson and Rundström (1988) observed that parents routinely stepped in as the spokespersons for their children (ages 5-15 years). Even when the doctor addressed the children, the mothers simply took their children's turn or came in right after. They then ratified and reinforced what their children said and explained what they meant, implying that the children cannot, or do not have the opportunity to, express it properly themselves (Linell, 1990).

In contrast, informal adult conversations, between friends in particular, often have a high degree of symmetry. Such dialogues are brought forward by both interlocutors in a cooperative way. The initiative is not continuously on the part of one interlocutor, but alternates in a fluent way. In this alternation, the speakers contribute to a mutually constructed interpretation of the situation at hand. As a consequence, they display their unfolding understanding of the joint discourse on a play-by-play basis, and ideas emerge in the process itself. The symmetrical dialogue should be considered a construction, even a 
co-construction of the two parties involved (Linell, 1990). (For additional analyses of power and dominance with reference to Mead's theory of symbolic interactionism, see Gregg, 1991; Hermans \& Kempen, 1993.)

As Sampson (1993) recently observed, Bakhtin apparently neglected the role of power in discussing dialogue. This observation may be supported by a brief return to Bakhtin's analysis of Dostoyevsky's The Double. From the beginning of the novel, there is an antagonistic relationship between Golyadkin and his double. The double goes to Golyadkin's house, takes his place, and even dresses himself in Golyadkin's clothes. In Golyadkin's work situation, the double competes with him so that the double gets an even better reputation in the eyes of the superiors than Golyadkin himself. The continuous rivalry results in Golyadkin's downfall at the end of the book. In other words, in his analysis of this novel, and others in Dostoyevsky's oeuvre, Bakhtin seemed to concentrate on the notion of (full-fledged) dialogue to the neglect of the apparent power differences and power games in which Dostoyevsky's characters are involved.

In sum, it can be concluded that there are two defining characteristics of dialogical relationships: intersubjective exchange and dominance. That is, dialogical relationships vary on a continuum ranging from symmetrical to asymmetrical. An interrogation is an example of a strongly asymmetrical dialogue, whereas an informal conversation among two friends is of a more symmetrical kind. The notion of dominance applies not only to actual interactions, but also to imaginal interactions. When somebody is under the spell of a fortune-teller's prediction, or under the dictates of an authoritarian father or mother, his or her imaginal dialogues may be highly asymmetrical. The productive imaginal contact a person has with a wise advisor, or the imaginal communication a scientist has with an inspiring colleague, represents dialogical contact that has a high degree of symmetry.

\section{The Dialogical Self: A Spatiotemporal Construction}

Guided by the polyphonic metaphor, Hermans et al. (1992) and Hermans and Kempen (1993) criticized the idea that the self is organized around one center or core. (Sampson, 1993, criticized the core conception on cultural grounds.) Just as in the polyphonic novel there is not one centralized author with a unifying view of the world, but rather a multiplicity of authors, so the self may be conceived of as a multiplicity of relatively autonomous "I positions" that are organized in an imaginal landscape. In this conception, the $I$ has the possibility to 
move, as in a space, from one position to the other in accordance with changes in situation and time. The I fluctuates among different, and even opposed, positions and has the capacity to imaginatively endow each position with a voice so that dialogical relations between positions can be established. The voices function like interacting characters in a story, involved in a process of question and answer, agreement and disagreement. Each character has a story to tell about its own experiences from its own stance. These characters exchange information about their respective Mes, resulting in a complex, narratively structured self. In this multiplicity of positions, some positions may become more dominant than others, so that the voices of the less dominant positions may be subdued.

In fact, the dialogical self, as formulated above, is a narrative translation of James's (1890) classic distinction between I and Me. As Sarbin (1986) proposed, the $I$ can be conceived as an active agent able to tell, as an author, a story about him- or herself as an actor. In an attempt to move beyond Sarbin's proposal, Hermans and Kempen (1993), guided by the polyphonic novel, conceived of the self not as one (centralized) $I$, but as a (decentralized) multiplicity of $I$ positions, among which dialogical relationships develop. The gist of this view is that the self is multivoiced. When people have developed one I position that they consider to be their "usual self," this is not to be mistaken for an essential unity of the self. Rather, as Sampson (1993) argued, the usual self is to be understood as the end point of a development that has been determined by social training in a culture that fosters a centralized idea of the self. In actual fact, the usual $I$ or any common selfdefinition may be overruled at times-for example, when the person is involved in an erotic adventure, in an extremely inspiring scientific discovery, in a burst of artistic creativity, in a situation in which feelings of revenge make for a decisive plan, or in an extraordinary experience under the influence of drugs.

There is an important difference between the dialogical self and recent formulations of the self by narrative psychologists. Sarbin (1990), Sarbin and Mancuso (1983), Bruner (1986), and Gergen and Gergen (1988), some of the main advocates of a narrative approach, have emphasized the temporal dimension of narratives. Bruner's (1986) sentence "The king died, and then the queen" nicely illustrates this emphasis. Gergen and Gergen (1988), in their conception of self-narrative, also saw "time" and "coherence among events" as the defining characteristics of narrative and classified narratives according to their movement over time toward a desirable end state.

The dialogical self certainly acknowledges the temporal dimension as a constitutive feature of stories or narratives. Without time, 
there is no story. However, in correspondence with Bakhtin's (1929/ 1973) emphasis on the spatial dimension, time and space are of equal importance for the narrative structure of the dialogical self. The spatial nature of the self is expressed in the term position, a term that is more dynamic and flexible than the traditional term role (cf: Harre \& Van Langenhove, 1991). Bakhtin (1929/1973) emphasized the spatial nature of narrative by using the term juxtaposition. In this narrative spatialization, a plurality of voices that are neither identical nor unified, but rather heterogeneous and even opposed, is supposed. As part of a narrative juxtaposition, characters are portrayed as conversing with other, often opposing characters. As Bakhtin described, it is even possible to translate temporal relations into spatial structures by juxtaposing different periods of life. When moving in an imaginal space, people can shift from the present to the past or future and back to the present. When they come back to the present, they have more or less been changed by the dialogical process itself. For example, people can imag-inatively move to a future point in time and speak to themselves about the sensibility of what they are doing now in the present situation. This position, some point in the future, may help them evaluate their present activities from a long-term perspective. The result may be that they consider their present self as being blind to more "essential" things.

Instead of a movement through time toward a desirable end state (Gergen \& Gergen, 1988), the Bakhtinian approach allows a more openended kind of narrative. According to this approach, there is not a continuous movement from a beginning to an end (e.g., the movie with an happy ending), but rather a combination of oppositional elements of a rather discontinuous nature, as can be seen in modern novelistic literature (e.g., Joyce's Ulysses). Of course, new combinations may emerge as the narrative develops, but there is no final combination that functions as an organizing principle of the story as a whole. Any final solution would be in contradiction with the openended nature of the polyphonic novel.

\section{THE SELF AS AN ORGANIZED PROCESS OF VALUATION: THE METHOD OF SELF-CONFRONTATION}

In this section, I present the concept of valuation as an active I process of meaning construction of a narrative kind and introduce a selfconfrontation method in order to study the self-narrative as multivoiced. This theory and method provide a framework for the study of an empirical finding, the phenomenon of dominance reversal, or an un- 
expected and drastic change in the dominance relation between opposed positions in the self. For more comprehensive discussion and illustration of the self-confrontation method for assessing valuations and their change over time, see Hermans (1995) and Hermans and Hermans-Jansen (1995).

\section{Valuation System: Self as a Composite of Narrative Fragments}

Valuation theory (Hermans, 1987a, 1987b, 1988, 1989; Hermans \& Van Gilst, 1991) was originally developed for the study of individual experiences, their ordering into a narrative structure, and their development over time. In this theory, inspired by James (1890) and MerleauPonty (1945/1962), the self is conceived of as an organized process of valuation. The process aspect refers to the historical nature of human experience and implies a specific spatiotemporal orientation: The embodied person lives in the present and is therefore oriented toward the past and the future from a specific point or position in time and space. The organizational aspect is intended to emphasize that the person, through the process of self-reflection, creates a composite whole containing contrasting experiences associated with different positions in time and space.

The central concept of valuation is an active process of construction of personal meaning and reflects the agentic character of the $I$. It is an open concept and includes anything people find to be of importance in the process of selecting and organizing the events as parts of their self-narratives. A valuation is any unit of meaning that has a positive (pleasant), negative (unpleasant), or ambivalent (both pleasant and unpleasant) value in the eyes of the individual. It includes a broad range of phenomena: a precious memory, an impressive event, a difficult problem, a beloved person, an unreachable goal, the anticipated death of a significant other, and so forth. In the process of selfreflection, specific valuations are selected and organized into a system. Depending on the individual's position in space and time, different valuations may emerge.

On the basis of the foregoing considerations, it is assumed that the self is multivoiced with different characters, each having his or her own story to tell. This means that the self can be conceived of as an imaginal landscape composed of different $I$ positions. That is, the $I$ has the possibility to move, as in a space, from one position to another, to and fro, in accordance with changes in the situation. As different voices, these positioned I's may tell stories about their re- 
spective Mes and their worlds, resulting in a complex, narratively structured dialogical self. The different $I$ positions function as different centers of self-organization and consequently construe different valuation systems. Because the positions in the self are not of equal dominance, one valuation system may have a more prominent place in the self as a whole than the other systems.

\section{The Self-Confrontation Method: Construing Opposing Systems of Valuations}

For present purposes, an adapted version of the self-confrontation method, based on valuation theory, is devised. The self-confrontation method is an idiographic instrument that invites the individual to investigate his or her valuation system in collaboration with a psychologist (Hermans, 1987b, 1988, 1991). The procedure includes three steps:

1. Identification of two opposing positions in the self that are currently relevant in the subject's life;

2. Formulation of a valuation system from the perspective of each position separately; and

3. Assessment of the cognitive, affective, and behavioral implications of the valuations of the two systems.

To understand the procedure, consider the following example. First, a subject is invited to select two opposing sides of her personality, with one side more or less dominating the other. Suppose the subject chooses "my open side" and "my closed side" as opposites, with the open side as dominant.

Next, a series of open-ended questions (Table 1) is presented to the subject for the elicitation of her valuations. The questions ask for relevant issues from the past, present, and future. They invite the subject to reflect on her life situation in such a way that she feels free to mention those concerns that are most relevant from her present perspective. She is encouraged to phrase the valuations in her own terms so that the formulation reflects her intended meaning. The typical form of the valuation is a sentence. For present purposes, the subject is invited to formulate six valuations from the perspective of her "open" position (two valuations referring to her past, two referring to her present, and two referring to her future). Then, the same questions in Table 1 are read again to the subject, but this time the subject is asked to formulate six valuations from the perspective of 
TABLE 1 Questions of the Self-Confrontation Method

\section{Set 1: The past}

These questions are intended to guide you to some aspect of your past life that is of great importance to you.

- Was there something in your past that has been of major importance or significance for your life and that still plays an important part today?

- Was there, in the past, a person or persons, an experience, or a circumstance that greatly influenced your life and still appreciably affects your present existence?

Your are free to go back into the past as far as you like.

\section{Set 2: The present}

This set is also composed of two questions that will lead you, after a certain amount of thinking, to formulate a response:

- Is there in your present life something that has major importance for or great influence on your existence?

- Is there in your present life a person or persons or a circumstance that exerts a significant influence on you?

\section{Set 3: The future}

The following questions are again intended to guide you to a response:

- Do you foresee something that will have major importance for or great influence on your future life?

- Do you feel that a person or persons or a circumstance will have a great influence on your future life?

- Is there a future goal or object that you expect to play an important role in your life?

You are free to look as far ahead as you wish.

her "closed" position. (Note that there is no one-to-one relation between question and answer. The questions are used simply to invite the person to self-reflect.)

Next, the subject is invited to concentrate on the week prior to the investigation and rate (on a 0-9 scale) each of the 12 valuations according to two dimensions: (a) how dominant the particular valuation has been in her thinking, feeling, and action ("the influence a particular valuation had on your thinking, feeling, or action, such that it suppresses other thoughts, feelings, and actions") and (b) how meaningful the particular valuation has been for her thinking, feeling, and action ("To what extent was this valuation meaningful, that is, to what extent did it contribute to the quality of your life?").

Finally, the subject is asked to keep a diary for 3 weeks. That is, at the end of each day, she concentrates for a while on the two sets of valuations, relates them to the events of that day, and keeps daily notes about the process as a whole. At the end of the week, she again rates all valuations on dominance and meaningfulness, and this is 
continued for 3 full weeks after the self-investigation. After these 3 weeks, during which there is no contact between subject and investigator, the investigator receives the diary from the subject (with her self-reflections at the end of each day) and the weekly judgments on dominance and meaningfulness (the first is a baseline, and the second, third, and fourth are successive assessments). In a final session, after the 3-week period, the investigator discusses the results with the subject and asks for some additional information.

\section{THE PHENOMENON OF DOMINANCE REVERSAL}

The idiographic study presented here is part of a larger project on human valuation (Hermans, 1987a, 1987b, 1988, 1992a, 1992b, 1992c). The subject, Nicole, a 23-year-old woman, is a part-time social worker in an institution for delinquents. She has no psychiatric history, and has never been in psychotherapy. Together with other people, she volunteered because she was interested in the project, and she did not receive any financial or material reward.

In response to the investigator's question concerning two opposite sides of her personality, Nicole explained that she saw herself as mainly being a "self-assertive" person but as having a less dominant, "anxious-uncertain" side as well. Responding to the same set of questions (Table 1) from the two positions, Nicole formulated two completely different sets of valuations referring to different memories of the past, different concerns in the present, and different expectations of the future (Table 2). The valuations from the self-assertive position mainly represented a fairly optimistic outlook on the world, whereas the valuations from the uncertain-anxious position referred to more negative experiences. At the same time, the valuations were not simply different in the way that the valuation systems of two unrelated people may be different. Rather, the two "characters" opposed one another in a dialogical way, sometimes even disagreeing with each other (e.g., Valuations 3 and 10, and 6 and 11, in Table 2).

The dominance and meaningfulness of the valuations of the two positions are presented in Figure 1, which compares mean dominance ratings for the six valuations of the self-assertive position with mean dominance ratings for the six valuations of the uncertain-anxious position at four successive measurements (Times 1-4). Figure 1 also shows the mean ratings for meaningfulness at the same four measurements.

At Time 1, the valuations of Nicole's self-assertive $I$ were, as a group, higher in dominance than the valuations of her closed $I$. This result, representing the baseline, was expected, given that Nicole her- 
TABLE 2 Valuations from the Self-Assertive and the Uncertain-Anxious Positions

Valuations from the self-assertive position

Past 1. As the oldest, I've always carried much responsibility for my younger sister; this has laid the basis for caring and feeling responsible for others.

2. When I want to achieve something, I often choose the hardest way (e.g., combining studies, chairing the student league, and an active social life); when this succeeds, I become more self-assertive.

Present 3. I have a relationship with a man in which I can totally be myself (in both my good and bad moods) and be accepted, and I derive certainty from that.

4. After a period in which I felt threatened by an ex-patient, I have deliberately looked for another living place; there I have found my rest and freedom again.

Future 5. I am aspiring to a leadership position; I am planning to pursue management training, so that I can start with this job after about 8 years from now.

6. Although my boyfriend also has a relationship with another woman, I expect that he will eventually choose me, so that we will have a future together.

\section{Valuations from the uncertain-anxious position}

Past 7. Only now has my mother started to tell what happened in her family (e.g., incest): This contrasts sharply with the warm and enriching education I have enjoyed.

8. The experiences my mother is telling of evoke in me anxiety about her as a child and respect and appreciation for the person she is now.

Present 9. After a very difficult period, my sister has started to travel together with her friend, so that I am missing a period of her development. Being involved with her, I want to care and to control; if this is not possible, I feel scared, uncertain, and jealous.

10. The fact that my relationship [with her boyfriend] is illegitimate evokes in me feelings of loneliness, powerlessness, dependency, and jealousy.

Future 11. If my friend does not choose me, this relationship will break me so that my trust in relationships will be gone, and also the basic trust in myself.

12. I am scared that somebody who is dear to me will suddenly die (e.g., my parents, sister, or a friend), so that I no longer have the situation under control and feel loneliness, sorrow, pain, and desolation. 


\section{DOMINANCE}

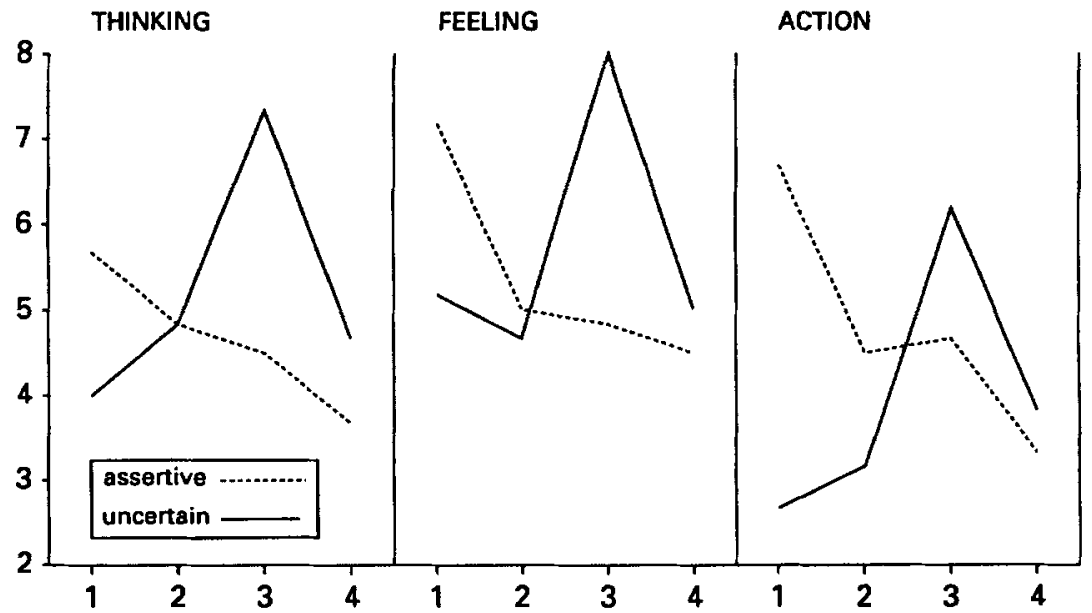

MEANINGFULNESS

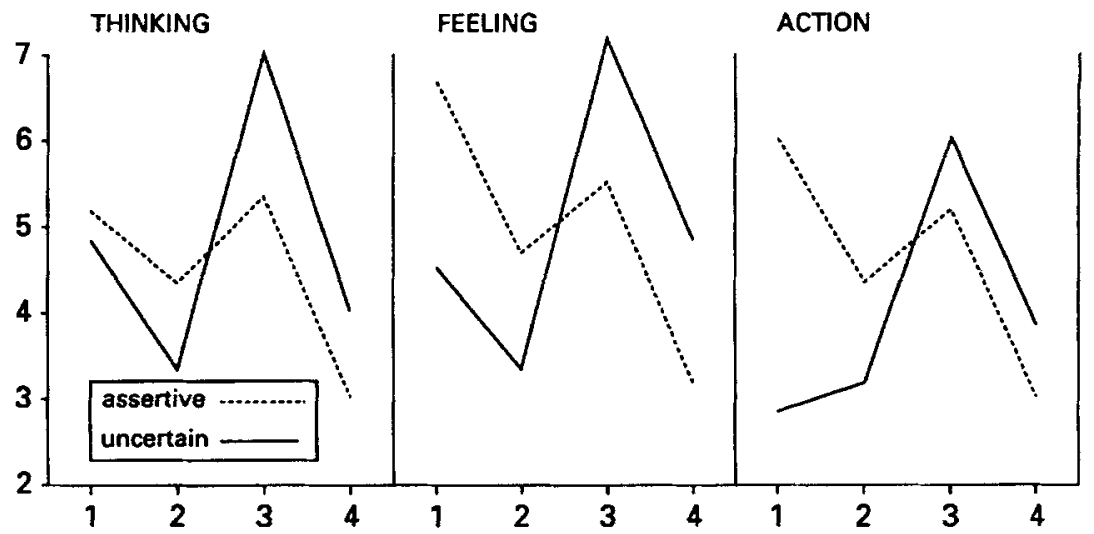

FIGURE 1 Dominance and meaningfulness ratings of thinking, feeling, and action for the self-assertive and uncertain-anxious positions at Times $1-4$.

self had selected the two positions as differing in dominance. The differences were in the expected direction for thinking, feeling, and action, although they were largest for action. The extremely low dominance level of the uncertain position for action at Time 1 suggests that Nicole did not express the uncertain-anxious part of her self in her behavior. 
The most conspicuous finding, however, was the strong upward tendency of the uncertain-anxious position, and the strong downward tendency of the self-assertive position, with a crossing of the lines at Time 2 or between Times 2 and 3. These tendencies and crossings were consistently found for thinking, feeling, and action. In the period of study, the initial dominance of the self-assertive position was followed by a successive dominance of the uncertain-anxious position. In this crossing of the lines, the phenomenon of dominance reversal was reflected. The question can be asked, however, to what extent such a reversal has significance or meaning for the person. This question may be answered by inspection of the meaningfulness ratings.

The results for meaningfulness, at the lower part of Figure 1, are basically the same as those for dominance. Again, we see a decrease for the self-assertive position, an increase for the uncertain-anxious position, and a crossing of the two lines between Times 2 and 3 . Although the valuations of the self-assertive position were highly meaningful at Time 1, they decreased in meaningfulness over time, whereas the valuations of the uncertain-anxious position tended toward an increase in meaningfulness. Note that although the self-assertive position included typically positive (pleasant) valuations and the uncertain-anxious position mainly negative (unpleasant) valuations, the former showed a decrease in meaningfulness and the latter some increase in meaningfulness.

In her final discussion with the investigator after the 3-week period, Nicole said she was aware of the increased involvement in her uncertain-anxious position but was not able to point to one main event that could account for this change. Inspection of her diary led to similar conclusions. In the first 2 weeks of the investigation, she referred alternately to valuations from the two positions, without emphasizing one event that could account for the uncertain-anxious position's increased dominance and the self-assertive position's decreased dominance.

The finding of dominance reversal is in agreement with findings from another subject (Hermans \& Kempen, 1993), who also showed a clear dominance reversal in the absence of a particular event that could be considered the cause of this reversal. The most plausible interpretation is that during the process of communicative self-reflection (as in the self-confrontation procedure), a subordinate position, granted a voice, asks for more attention than usual and, in fact, receives more explicit attention than earlier. As a result, this position becomes more salient in the person's self-organization than the position that was originally dominant. 
A more conspicuous development in Nicole's case, however, was the simultaneous decrease of both positions between Times 3 and 4, in both dominance and meaningfulness. What was the reason for the sudden and simultaneous decreases? At the beginning of the week, between Times 3 and 4, Nicole wrote,

By reading the valuations over and over and by being concerned with them, I am becoming aware that I am feeling less and less happy with the complex relationship that I have with my boyfriend [see Valuations 10 and 11 in Table 2]. Friday night was therefore very crucial. ... The man who brought me home [someone other than her boyfriend] was allowed to stay. I have known this man for a long time, as a good friend of my cousin. Over the last days we have had a lot of contact, spending many hours in telephone conversation. This contact makes me feel good, but it also creates a lot of confusion. I feel restless and fearful, because I do not have my emotions under control. The freedom that I am supposed to have in the relationship with my boyfriend [Valuation 3] is simply not there. ... It becomes more and more clear to me that I do not want to have a relationship in this way and I feel a very strong need to keep my boyfriend at a distance. At this moment I feel strong enough to say to him ... I hope that I can hold onto this feeling, because I finally want to cut the knot, as he is not able to do this.

Two days later, her boyfriend visited her and she related this meeting in the diary:

Yesterday evening my boyfriend came. I had a very difficult day behind me and finally wanted to cut the knot. I felt very strong in this. When he was there, I could not express one word. After 10 minutes of silence, I started to cry very hard. I made it clear to him that I do not want to go on in this way, that I can't! I've told him also about the other man. . . . It's suddenly so clear to me that I can't bear this relation [with her boyfriend] any longer.

Two days later, she concluded, "For two long years I did not dare to make this step. For a part, being involved in this self-investigation has helped me to get clear that I can't bear this situation." One day later, she decided also to distance herself from the second man, with whom she had entered into a close relationship:

Yesterday evening the other man came over for dinner. I felt very bad. He was very sweet to me. I fought against my sorrow and therefore couldn't get in touch with my emotions. A lot of talking, a lot of wine; he spent the night . . . all very confusing. l've slept for 
some 20 minutes. This morning it became clear to me that it is all going too quick, he is getting too close. I made this clear to him, which was painful for him. I've put him at a distance. The initiative is from me ... I am now taking the time to work out my sorrow. I am aware that $I$ must do this alone ... . This morning I was very scared to go to my work ... . , afraid of questions, afraid that I would not be strong enough. I was at the point of calling in sick ... However, this is not my style. I went, worked very hard and came home very tired. I canceled my appointments for tonight. . . . I am suppressing my sorrow very strongly.

As the last notes suggest, Nicole felt under threat of becoming overwhelmed by the negative feelings implied by the second position, the uncertain-anxious side, and therefore suppressed these feelings in order to maintain herself. Although the valuations of the uncertainanxious position were increasingly influential and reached a peak in dominance at Time 3 , there was a remarkable decrease in their dominance at Time 4 . This bending of dominance can therefore be understood as part of a process of self-organization: By suppressing the valuations of the uncertain-anxious position, Nicole countered the threat of disorganization of the self as a whole.

The preceding notes from the diary suggest that the drastic changes in dominance and meaningfulness, including Nicole's decision to break off the relationship with her boyfriend, were not reducible to any form of efficient causation. Take, for example, the influence of the second man. Can his influence be considered the cause of the remarkable changes in dominance and meaningfulness? The answer must be that this man did not function as the sole cause, and not even as the primary cause. Nicole related that before she slept with this man, she had increasingly felt bad in the relationship with her boyfriend, making her more open to the man's overtures. This increase of bad feeling was, in turn, preceded by the process of self-reflection that was part of the self-investigation. The notes in the diary, rather than pointing to a specific causal influence, suggest a highly complex process of selforganization with a multitude of interacting forces.

In fact, this idiographic study reveals two principles at work that were discussed at the beginning of this article. The principle of tension reduction, which received much attention from early social psychologists, is manifest in the simultaneous decrease in dominance of the two positions in this case. The idea that polar opposites are mutually complementing, emphasized by a diversity of clinical theorists, received equally empirical support in our study. The uncertainanxious position, although associated mainly with negative and pessi- 
mistic valuations, was experienced as increasingly meaningful when it became more dominant in the self. This also suggests that this (unpleasant) position was felt as belonging to the self as an intrinsic and valuable counterpart, like the countermelody in a polyphonic composition or the antagonist in the polyphonic novel.

\section{THE SELF AS A PROCESS OF ORGANIZATION AND REORGANIZATION}

On the basis of the notion of the dialogical self, contrasting poles of a personal construct may be conceived of as voiced $I$ positions that not only are intersubjectively related, but also differ in their relative dominance. As $I$ positions the construct poles may be "juxtaposed" in a self-investigation and both invited to tell their own story about themselves in terms of a system of valuations. In the idiographic study presented to illustrate this theoretical framework, the relative dominance and meaningfulness of the valuations of the positions were followed over time and a drastic change in the dominance relations, labeled a "dominance reversal," was observed. Although the change in the relative dominance of the two positions was radical, it was not possible to find an external event that could be considered the sole cause of the reversal in terms of an antecedent-consequent relationship. Even the simultaneous decrease in the dominance of both positions seen in the last week of the investigation was not simply attributable to one specific external event. As the diary notes suggested, this change was rather part of the subject's decision to break off the relationship with her boyfriend, a decision that was made in a turbulent period of her life. Given the lack of clear causality, what is the nature of this change and what are its theoretical implications for the psychology of the self? In order to address this question, it may be profitable to return to the fertile work of William James.

In Varieties of Religious Experience (1902/1982), James was even more interested in the phenomenon of radical change than he was in his earlier work. He was interested not only in the religious conversions and counterconversions of historical figures, but also in instances of sudden change in the selves of ordinary people. An example is his discussion of a case of "falling out of love." It concerned a man who suddenly stopped his relationship with a woman with whom he had fallen in love 2 years previously. When the man looked back to this period, he described that he had fallen violently in love with a woman who had "a spirit of coquetry." Although he secretly knew that she was not the right person for him, he fell into a regular fever and 
could think of nothing else. After a long period of being plagued by jealousy and contempt for his own uncontrollable weakness, there was a sudden change:

The queer thing was the sudden and unexpected way in which it all stopped. I was going to my work after breakfast one morning, thinking as usual of her and of my misery, when, just as if some outside power laid hold of me, I found myself turning round and almost running to my room, where I immediately got out all the relics of her which I possessed, including some hair, all her notes and letters, and ambrotypes on glass. The former I made a fire of, the latter I actually crushed beneath my heel, in a sort of fierce joy of revenge and punishment. I now loathed and despised her altogether, and as for myself I felt as if a load of disease had suddenly been removed from me. That was the end. (James, 1902/1982, p. 180, emphasis added)

James considered this case "an unusually clear example of two different levels of personality, inconsistent in their dictates, yet so well balanced against each other as for a long time to fill the life with discord and dissatisfaction" (p. 180). James used the phrase "unstable equilibrium" to characterize the specific organization of the self: "At last, not gradually, but in a sudden crisis, the unstable equilibrium is resolved" (p. 180). (For a recent discussion of the notion of equilibrium in the self, see Schwalbe, 1991).

What James described in terms of "two different layers of personality" I phrase in the present framework as two opposing I positions. Whereas in James's case a reversal of two layers occurred after a period of unstable equilibrium, in the case of Nicole there was a dominance reversal of two positions. There is also a significant difference between James's description and mine. Whereas James described a person showing a radical change in a spontaneous crisis, Nicole initiated a dominance reversal in a period of explicit and systematic selfreflection arranged in a project conducted conjointly by psychologist and subject. The data from the idiographic study of Nicole suggest that if one pole of a pair of opposites is subordinated or suppressed in a particular period, it may become strongly dominant at some later point in time. Although we do not fully understand what precisely determines the reversal of dominance, when it takes place, and by whom it takes place, the reversal phenomenon points to the relevance of dynamic psychological conceptions of the self, in which the possibility of radical change of oppositional poles in seemingly stable selfnarratives is taken into account. The existence of the reversal phenomenon suggests that people's usual self-definition is based on a 
temporary equilibrium of bipolar structures, rather than on unipolar stability of traits.

It is in the spirit of recent psychological discussions of the self to concentrate not only on its stability, consistency, and coherence, but also on the possible fertility of its instability, inconsistency, and incoherence (e.g., Hermans \& Kempen, 1993; Sampson, 1985; Schwalbe, 1991). Already some decades ago, one of the most prolific writers on the subject, Gordon Allport, argued for the necessity of studying the self in its dynamic and organizational aspects. In Becoming (1954), Allport's emphasis was clearly on the unity and synthesis of the self. However, speaking about the "complexity and liability of the organizational process," Allport remarked,

Becoming is not a mere matter of forging links to a chain. It sometimes involves the shifting of dominance from segmental systems to comprehensive systems, or from one comprehensive system to another. Just why or how such shifts occur we cannot say. When they are better understood we can align them with our discussions of determinism and freedom. (Allport, 1954, p. 87)

I expect that one of psychology's future challenges will be to illuminate unpredictable but significant moments of becoming.

\section{REFERENCES}

Adler, A. (1922). Uber den nervösen Charakter [On the nervous character] (3rd ed.). Munchen, Germany: Berg-mann.

Allport, G. W. (1954). Becoming: Basic considerations for a psychology of personality. New Haven, CT: Yale University Press.

Angyal, A. (1965). Neurosis and treatment: A holistic theory. New York: Wiley.

Atonsson, K., \& Rundstrom, B. (1988). Child discourse and parental control in pediatric consultations. Text, 8, 159-189.

Bakan, D. (1966). The duality of human existence. Chicago: Rand-McNally.

Bakhtin, M. (1973). Problems of Dostoyevsky's poetics (2nd ed.). R. W. Rotsel, Trans. Ann Arbor, MI: Ardis. (Original work published 1929)

Berne, E. (1972). What do you say after you say hello? New York: Grove Press.

Bruner, J. (1985). Vygotsky: A historical and conceptual perspective. In J. V. Wertsch (Ed.), Culture, communication and cognition: Vygotskian perspectives (pp. 21-34). Cambridge, England: Cambridge University Press.

Bruner, J. S. (1986). Actual minds, possible worlds. Cambridge, MA: Harvard University Press.

Cassirer, E. (1955). The philosophy of symbolic forms: Vol. 2. Mythical thought. New Haven, CT: Yale University Press.

Caughey, J. L. (1984). Imaginary social worlds: A cultural approach. Lincoln, NE: University of Nebraska Press.

Deikman, A. J. (1971). Bimodal consciousness. Archives of General Psychiatry, 25, 481-489. 
Deikman, A. J. (1976). Bimodal consciousness and the mystic experience. In Ph. R. Lee, R. E. Ornstein, D. Galin, A. J. Deikman, \& Ch. T. Tart (Eds.), Symposium on consciousness (pp. 67-88). New York: Viking Press.

Fairbairn, W. R. D. (1952). Psychoanalytic studies of the personality. London: Routledge \& Kegan Paul.

Festinger, L. (1957). A theory of cognitive dissonance. London: Tavistock.

Florenskaya, T. A. (1989). Psychological problems of dialogue in light of the ideas of M. M. Bakhtin and A. A. Ukhtomskii. Soviet Psychology, 27, 29-40.

Fowler, J. (1981). Stages of faith. New York: Harper \& Row.

Gergen, K. J., \& Gergen, M. M. (1988). Narrative and the self as relationship. Advances in Experimental Social Psychology, 21, 17-56.

Gregg, G. S. (1991). Self-representation: Life narrative studies in identity and ideology. New York: Greenwood Press.

Guntrip, H. (1971). Psychoanalytic theory, therapy, and the self. New York: Basic Books.

Gutmann, D. L. (1980). The post-parental years: Clinical problems and developmental possibilities. In W. H. Norman \& T. J. Scaramella (Eds.), Mid-life: Developmental and clinical issues (pp. 38-52). New York: Bruner/Mazel.

Harré, R., \& Van Langenhove, L. (1991). Varieties of positioning. Journal for the Theory of Social Behavior, 21, 393-407.

Heider, F. (1958). The psychology of interpersonal relations. New York: Wiley.

Hermans, H. J. M. (1987a). Self as organized system of valuations: Toward a dialogue with the person. Journal of Counseling Psychology, 34, 10-19.

Hermans, H. J. M. (1987b). The dream in the process of valuation: A method of interpretation. Journal of Personality and Social Psychology. 53, 163-175.

Hermans, H. J. M. (1988). On the integration of idiographic and nomothetic research method in the study of personal meaning. Journal of Personality, 56, 785-812.

Hermans, H. J. M. (1989). The meaning of life as an organized process. Psychotherapy, 26, $11-22$.

Hermans, H. J. M. (1991). The person as co-investigator in self-research: Valuation theory. European Journal of Personality, 5, 217-234.

Hermans, H. J. M. (1992a). The person as an active participant in psychological research. American Behavioral Scientist, 36, 102-113.

Hermans, H. J. M. (1992b). Telling and retelling one's self-narrative: A contextual approach to life-span development. Human Development, 35, 361-375.

Hermans, H. J. M. (1992c). Unhappy self-esteem: A meaningful exception to the rule. Journal of Psychology 126, 555-570.

Hermans, H. J. M. (1995). From assessment to change: The personal meaning of clinical problems in the context of self-narrative. In R. A. Neimeyer \& M. J. Mahoney (Eds.), Constructivism in psychotherapy (pp. 247-272). Washington, DC: American Psychological Association.

Hermans, H. J. M. \& Hermans-Jansen, E. (1995). Self-narratives: The construction of meaning in psychotherapy. New York: Guilford Press.

Hermans, H. J. M, \& Kempen, H. J. G. (1993). The dialogical self: Meaning as movement. San Diego, CA: Academic Press.

Hermans, H. J. M., Kempen, H. J. G., \& Van Loon, R. J. P. (1992). The dialogical self: Beyond individualism and rationalism. American Psychologist, 47, 23-33.

Hermans, H. J. M., \& Van Gilst, W. (1991). Self-narrative and collective myth: An analysis of the Narcissus story. Canadian Journal of Behavioural Science, 23, 423-440.

Jacobson, E. (1964). The self and the object world. New York: International Universities Press.

James, W. (1890). The principles of psychology (Vol. 1). New York: Macmillan. 
James, W. (1982). The varieties of religious experience: $A$ study in human nature. New York: Penguin Books. (Original work published 1902)

Jung, C. G. (1959). Mandalas. In Collected works (Vol. 9, Part 1). Princeton, NJ: Princeton University Press.

Kelly, G. A. (1955). The psychology of personal constructs. New York: Norton.

Klages, L. (1948). Charakterkunde [Characterology]. Zurich, Switzerland: Hirzel.

Klein, M. (1948). Contributions to psychoanalysis 1921-1945. London: Hogarth Press.

Linell, P. (1990). The power of dialogue dynamics. In I. Markova \& K. Foppa (Eds.), The dynamics of dialogue (pp. 147-177). New York: Harvester Wheatsheaf.

Loevinger, J. (1976). Ego development. San Francisco, CA: Jossey-Bass.

McAdams, D. P. (1985). The "imago": A key narrative component of identity. In P. Shaver (Ed.), Self, situations, and social behavior. Review of personality and social psychology (Vol. 6, pp. 115-141). Beverly Hills, CA: Sage.

Merleau-Ponty, M. (1962). Phenomenology of perception (C. Smith, Trans.). London: Routledge \& Kegan Paul. (Original work published 1945)

Osgood, C. E., \& Tannenbaum, P. H. (1955). The principle of congruity in the prediction of attitude change. Psychological Review, 62, 42-55.

Sampson, E. E. (1985). The decentralization of identity: Toward a revised concept of personal and social order. American Psychologist, 11, 1203-1211.

Sampson, E. E. (1993). Identity politics: Challenges to psychology's understanding. American Psychologist, 48, 1219-1230.

Sarbin, Th. R. (1986). The narrative as a root metaphor for psychology. In Th. R. Sarbin (Ed.), Narrative psychology: The storied nature of human conduct (pp. 3-21). New York: Praeger.

Sarbin, Th. R. (1990). The narrative quality of action. Theoretical and Philosophical Psychol$o g y, 10,49-65$.

Sarbin, Th. R., \& Mancuso, J. C. (1983). The self-narrative in the enactment of roles. In Th. R. Sarbin \& K. Scheibe (Eds.), Studies in social identity (pp. 254-273). New York: Praeger.

Schwalbe, M. L. (1991). The autogenesis of the self. Journal for the Theory of Social Behavior, 21, 269-295.

Steiner, C. M. (1974). Scripts people live. New York: Grove Press.

Sullivan, H. S. (1953). The interpersonal theory of psychiatry. New York: Norton.

Vasil'eva, I. I. (1988). The importance of M. M. Bakhtin's idea of dialogue and dialogic relations for the psychology of communication. Soviet Psychology, 26(3), 17-31.

Warneck, M. (1909). Der Religion der Batak [The religion of the Batak]. Leipzig, Germany: Weicher.

Watkins, M. (1986). Invisible guests: The development of imaginal dialogues. Hillsdale, NJ: Erlbaum.

Wertsch, J. V. (1991). Voices of the mind: A sociocultural approach to mediated action. London: Harvester Wheatsheaf.

Wrong, D. (1968). Some problems in defining social power. American Journal of Sociology, $73,673-681$. 